\title{
STREAMING-PLASMA MEASUREMENTS IN THE BASEBALL II-T MIRROR EXPERIMENT
}

C. C. Jasen, J. H. Foote, A. H. Futch, R. K. Goodman,

R. S. Hornady, J. F. Osher, and G. D. Yorter

Kay 9, 1977

Prepared for U.S. Energy Re search \& Development Administration under contract No. W-7405-Eng-48

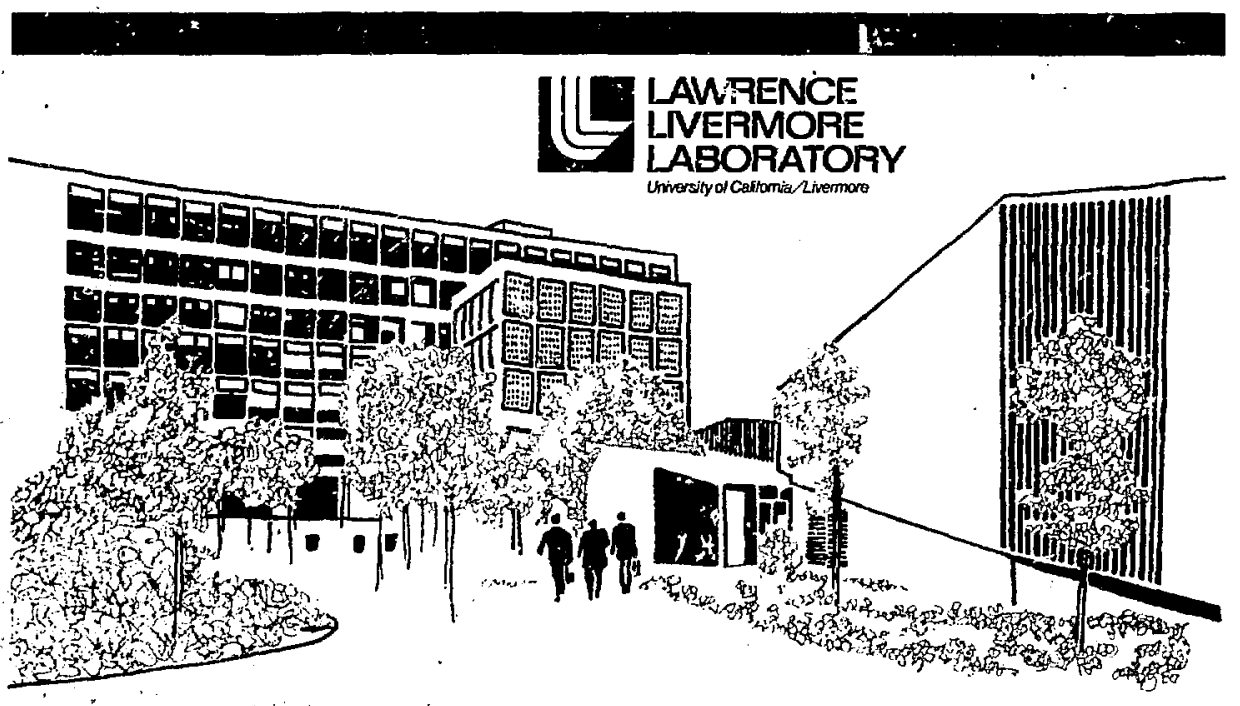


NuTICE

This report was prepared as an account of work sponsored by the United Slates Govemment. Neither the United States nor the United States Energy Rasearch \& Development Administration, noe eny of thelr employess, not any of their contractors, subcontractors, of thelr employees, makes any warenty, expres or implied, of asumes any legal llablitty of retponiblitty for the eccuracy, crmpleteness or usefuloex of any information, arparatus, nroduct ne ornees dixlosed, or represents that its use would not Inifige privately-owned rights.

\section{NOTICE}

Reference to a company or produce name does not imply approval or recommendation of the product by the University of California or the U.S. Energy Research 2. Development Administration to the exclution of others that may be suitable.

Printed in the United States of America Available from

National Technical Information Service

U.S. Department of Commerce

5285 Port Royal Road

Springfield, VA 22161

Price: Printed Copy $\$$; Misrofiche $\mathbf{5 3 , 0 0}$

\begin{tabular}{|c|c|c|c|}
\hline Poge Ranpe & $\begin{array}{c}\text { Domestic } \\
\text { Price } \\
\end{array}$ & Pape Range & $\begin{array}{l}\text { Domestlc } \\
\text { Price }\end{array}$ \\
\hline $001-025$ & 53.50 & $326-35 n$ & 10.00 \\
\hline 026-050 & 4.00 & $35 I-375$ & 10.50 \\
\hline $051-075$ & 4.50 & $376-400$ & 10.75 \\
\hline $076-100$ & 5.00 & $40 t-425$ & 11.00 \\
\hline $101-125$ & 5.50 & $426-450$ & 13.75 \\
\hline $126-150$ & 6.00 & $451-475$ & 12.00 \\
\hline 151-175 & 6.75 & $476-500$ & 12.50 \\
\hline $176-200$ & 7.50 & $501-525$ & 12.75 \\
\hline $201-225$ & 7.75 & $526-550$ & 13.00 \\
\hline $226-250$ & $\cdot 8.00$ & $551-575$ & 13.50 \\
\hline $251-275$ & 9.00 & $576-600$ & 13.75 \\
\hline $276-300$ & 9.25 & . 601-up & 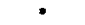 \\
\hline $301-325$ & 9.75 & & \\
\hline
\end{tabular}

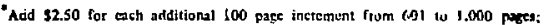
add $\mathbf{4 . 5 0}$ for each additional ton page increrient aver 1,000 pages. 


\section{㢟 \\ LAWRENCE LVERMORE LABPARATORY \\ Universityol Catomia/Livermore, Callitornia/94550}

\section{UCRL-52279 \\ STREAMING-PLASMA MEASUREMENTS IN THE BASEBALL II-T MIRROR EXPERIMENT}

C. C. Damm, J. H. Foote, A. H. Futch, R. K. Goodnan,

R. S. Hornady, J. E. Osher, and G. D. Porter

MS. date: May 9, 1977

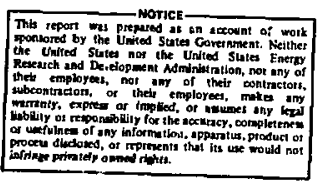




\section{Contents}

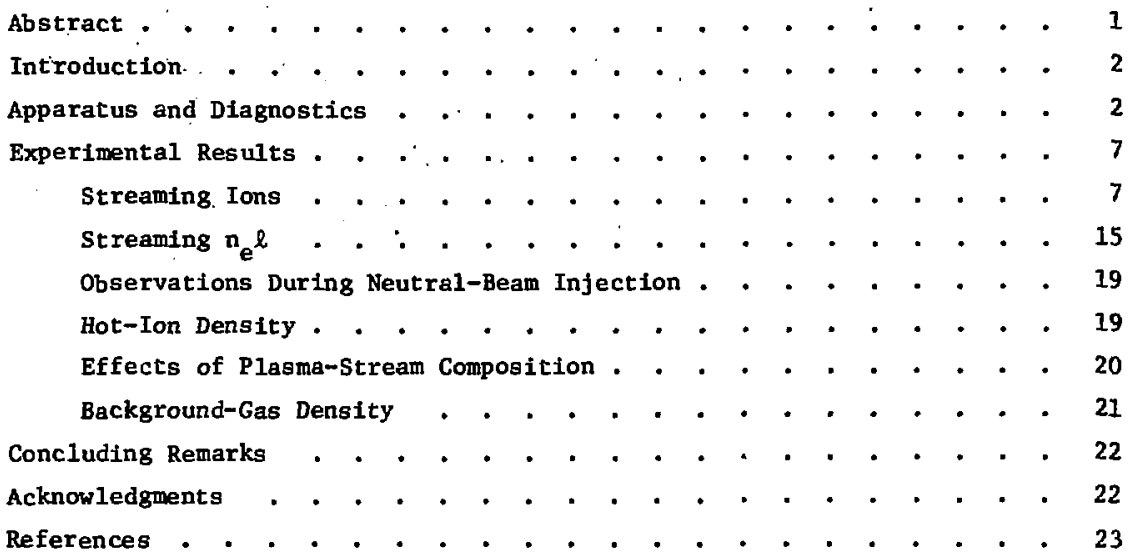




\section{STFEAMING-PLASMA MEASUREMENTS IN THE BASEBALL II-'T MIRROR EXPERIMENT}

\section{Abstract}

The warm plasma from a deutertumloaded titanlum washer gun, streaming along magnetic-field lines through the steady-state magnetlc well of Baseball II, has been examined for 1ta sultability in this experimental situation as a target plasma for hot-ion bulldup experiments and for microinstability control. The gun was positioned near the magnetic axis outside the mirror region. Measurements were made with gridded, end-1oss detectors placed outside the opposite mirror, a microwave interferometer, a beam-attenuation detector, and other dlagnostics. From the end-1oss-detector signals, we estimate that as much as $21 \mathrm{~A}$ of streaming-ion current passed from the gun through the far mirror region, with a measured mean Ion energy beyond the second mirror varying from 100 to $280 \mathrm{eV}$ (If singly charged). When profile measurements of the streaming-ion current made with the end-loss detectors are projected back along magnetic-fleld lines to the midplane, they Indicate that the stream dimensions at the midplane were approximately $14 \mathrm{~cm}$ horizontally (perpendicular to the direction of the streaming flow) and $\leq 7 \mathrm{~cm}$ vertically ${ }_{+}$This is a good match to the neutral beam for trapping purposes. The large differences between the dimenstons of the stream at the midplane, as obtained from the end-profile measurements, and the dimengtons of the emltting area of the streaming gin projected to the midplane along fleld lines from the opposite end suggest motion of the streaming plasma across magnetic-field 1Ines. Microwave measurements give $\mathrm{n}_{\mathrm{e}} \ell \approx 2 \times 10^{14} \mathrm{~cm}^{-2}$ through the streaming plasma In the horizontal direction, at an angle of $60^{\circ}$ to the stream flow. When $33 \mathrm{~A}$ of $10-\mathrm{keV} \mathrm{B}^{0}$ (equivalent current at mean energy) was infected across the streaming plasma, the bean was attenuated by about $12 \%$, and we observed an increase in the measured electron density of $3( \pm 1) \times 10^{12} \mathrm{~cm}^{-3}$. These experimental results show that the warm streaming plasma investigated has characteristies that appear suitable for both microinstab111ty control and for target initiation of neutral-beam trapping in the steady-state magnetic field of the Basebal1 II-T coil. 


\section{Introduction}

A principal purpose of the BasebaI1 II-T (BBII-T) * experiment at the Lawrence Livermore Laboratory (LLL) wias to start up a high-denstty, hot plasma in a steady-state magnetic field by trapping incident, highenergy neutral beams on a warm target plasma. 1 . Two target plasmas were developed for this purpose: a streamIng plasma from a standard $2 X I I B$ washer gun, 2,3 and a laser-initiated target plasma. ${ }^{1,4}$ In this report, we discuss our experimentation with the first of these.

* The designation "Baseball II-T" refers to the target-startup phase of Basebal1 II (BBII) experiments, which use the Baseball II superconducting coil.
The suppression of microinstability amplitudes in the 2XIIB experiment by introducing a warm streaming plasma ${ }^{5}$ has been attrłbuted to a partial filling of the pirror loss cone. 6 The need for a similar stream in BBIT-T provides additional interest in the streaming-plasma approach to providing a target plasma.

We have measured the parameters of the streaming plasma produced by a washer gun in the $B B I I-T$ experiment. This report, summarizing these measurements, is divided into three main sections: Apparatus and Diagnostics, Experimental Results, and then some Concluding Remarks.

\section{Apparatus and Diagnostics}

To create the warm streaming plasma in BBII-T, we employed a deuterlum-loaded titanium washer gun of the type regularly uged on 2XIIB. 2,3 The plasma pulses were 1 to 6 ms long. For most of our operation, the gun tip was positioned at the north wall of the vacuum chamber, 126 cm from the center of the magnetic well (the mitror is at $48 \mathrm{~cm}$ ). At this position, the ratio of the magnetis field at the mirror to that at the gun (B $B_{\text {mirror }} / \mathrm{B}_{\text {gim }}$ ) was 10.8 . This ratio could be easily varied by moving the gun in or out with respect to the center of the magnetic well.
The gun was first located on the magnetic axis, but was later moved $7.5 \mathrm{~cm}$ east, perpendicular to the magnetic axis, to free the axis for alignment purposes. It still was aimed at the center and was positioned on a field line in the hortzontal plane that passed only $0.4 \mathrm{~cm}$ from the center. In general, the experimental results are not noticeably different for this off-axis position, except that the measured profile is somewhac broader horizontally.

A Lawrence Berkeley Laboratory (LBL) 20-kev, 50-A Ion-source module was used to inject a neutral-hydrogen 
beam in ronfunction with the streaming plasma. This enabled us to check out the operation of the source in the presence of the BBII magnetic field and in coordination with the rest of the experimental apparatus. The beam proved useful as a diagnostic for the stream, and the beam-stream Interaction produced hot ions, many of which were then trapped in the magnetic field. The beam was usually operated at a source voltage of 12 to $15 \mathrm{kV}$, with an average of 22-A neutral current (equivalent) at $15 \mathrm{kV}$. This value for the beam current was obtained from calorimetric power measurements by assuming that all particles had the full beam energy. Actually, some of the beam particles had one-half or one-third the full ieam energy. Correcting for the beam composition, we obtain from the 22-A, 15-kV rasult a beam current of about $33 \mathrm{~A}$ at an average energy of approximately $10 \mathrm{keV}$.

Figure 1 shows horizontal and vertical views of the BBII-T apparatus and magnetic field, including the positions of diagnostics such as the gridded end-loss detectors, the horns of the microwave interferometer, the fast-atom detector (FAD); and also the plasma gun at its innermost position. These drawings, although somewhat schematic, are to scale. They demonstrate how, at the north mirror, the magnetic-field lines are spread out in the horizontal plane and are squeezed together in the vertical. The situation is reversed at the south mirror.

The two gridded-detector collector-plate sets used at the south wall are the south end-loss detector (SELD) and the vertical-fan end-loss detector ( $V-F E L D)$. The forwer has six long, thin, side-by-side collector plates (thin in the horizontal direction), and the latter has two plates as shown in Fig. 1(b) (also thin in the horizontal direction). The SELD plates are $1 \mathrm{~cm} \times 10 \mathrm{~cm}$, with about one-third of their height blocked by other apparatus. The V-FELD plates are $1.9 \mathrm{~cm} \times 8.3 \mathrm{~cm}$; only one has an unrestricted view of the plasma. A scale drawing of the important elements of the SELD is shown in F1g. 2. Screen characteristics and the customary biasing arrangement are also given.

Because of the high particle flux incident on the gridded detectors, we watched the detector signals and grid blases carefully for signs of problems like space-charge limitation and bias breakdown. At times, substantial decrease in blas level during a shot was observed, even after highercurrent voltage supplies had been Installed. When this happened, the measurements were repeated, possibly with somewhat different values of the negative voltages, until the blases held nearly constant during an entire 


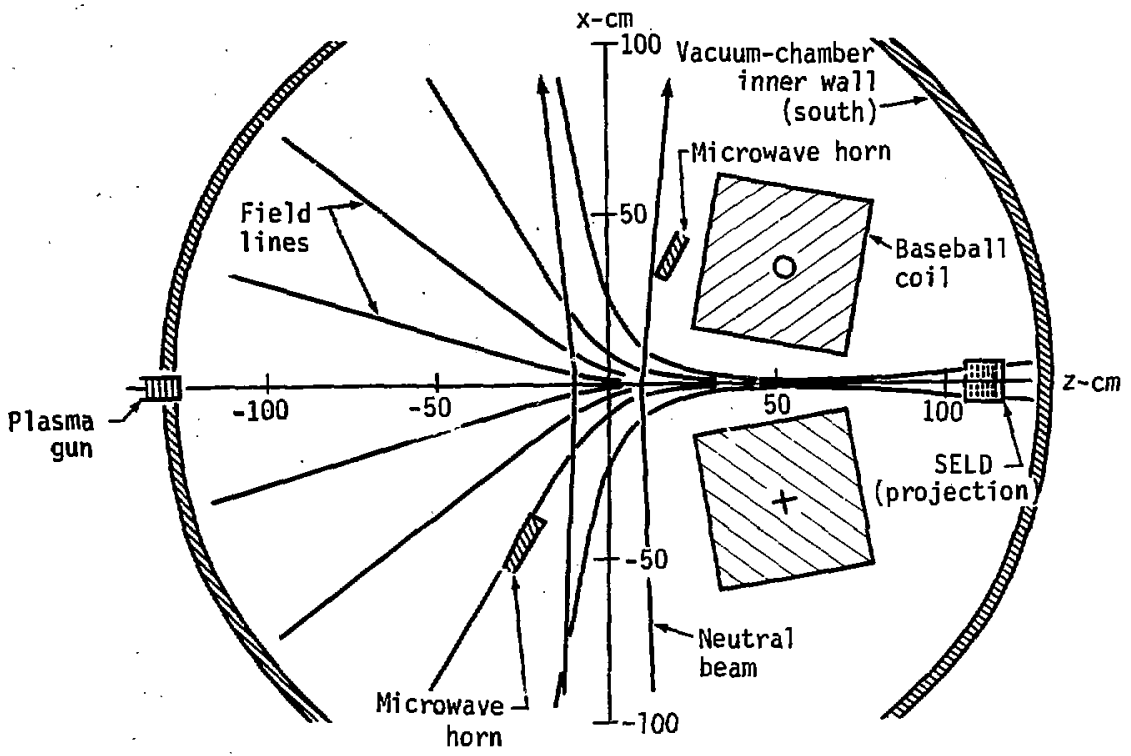

(a) Horlzontal view.

Fig. 1 The BBII-T coll, magnetic field, vacuum-chamber wall, plasma gun, and diagnostics (to scale). 


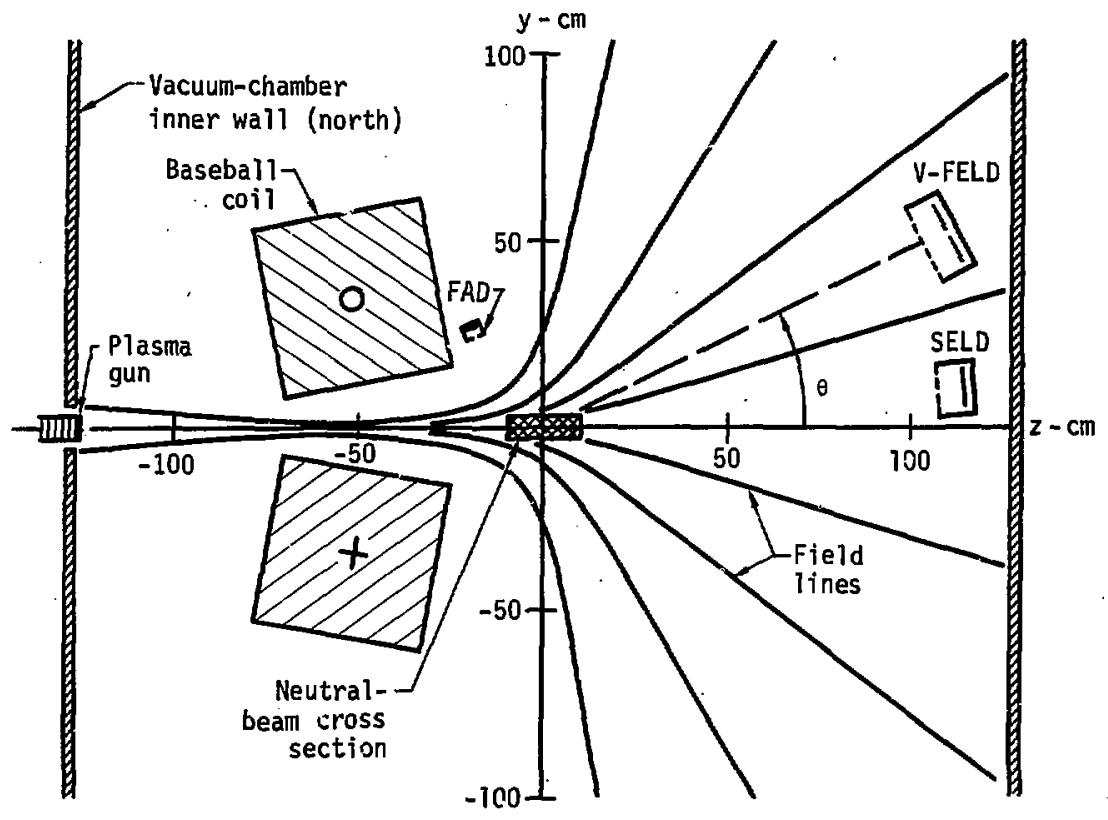

(b) Vertical view.

Fig. 1. (continued). 


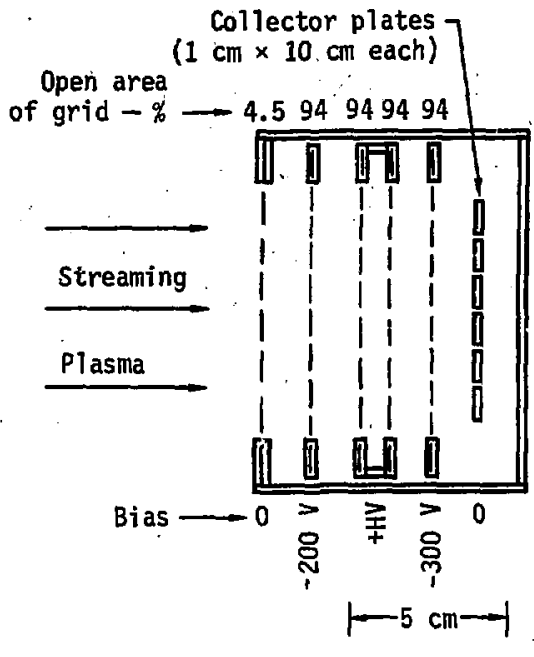

Fig. 2. Horfzontal cross section of the south end-1oss detector (SELD) (to scale), showing the grid and bias arrangement. The verticalfan end-loss detector (V-FELD) is similar except for larger-area grids and plates.

shot. We then had more confidence that the streaming plasma electrons were being repelled and that the remaining signals corresponded to streaming ions.

The density in the BBII-T experiment was measured using a 140-GHz (about 2-min) microwave interferometer. With this equipment, the signal that passes through the plasma undergoes two down-conversions in a balanced mixer-receiver to $60 \mathrm{MHz}$. This signal plus a reference signal, which is also down-converted to $60 \mathrm{MHz}$, are detected by a phase-comparatior circuit that provides both a $\sin \theta$ and a $\cos \theta$ output. The 60-MHz IF frequency is stabilized by a discriminator circuit that provides a feedback voltage to a voltage-controlled oscillator in the recelver, eliminating any drift in the 60-MHz IF frequency. In the experiment, we observed phase shifts of the microwave signal that passed through the plasma in the horizontal direction, at an angle of $60^{\circ}$ to the stream flow [see Fig, 1(a)]. Values of electron density times path length were then calculated using the equation

$$
\begin{aligned}
\mathrm{n}^{\ell\left(\mathrm{cm}^{-2}\right)} & =118.4 \times \text { frequency }(\mathrm{Hz}) \\
& \text { \% phase shift (radians). }
\end{aligned}
$$

A detailed description of the interferometer system is given in a separate report. 7

A beam-attenuation detector was positioned in the beam, downstream from the plasta [at $x \approx+219 \mathrm{~cm}$ in FIg. 1(a) 1. With it, we'monitored the neutral-beam intensity by measuring the flow of the secondary electrons produced at a metal plate, and we could detect the attenuation of the beam caused by the plasma.

Energetic charge-exchange neutrals leaving the plasma were detected with a surface-barrier detector and also with the fast-atom detector shown in Fis, 1(b). The surface-barrier detector was located below the plasma [at $y \approx-136 \mathrm{~cm} \mathrm{in} \mathrm{Fig.} \mathrm{1(b)].}$ 
For most of the results presented here, the fieli magnitude at the center of the magnetic well of the BBII superconducting coi? was in the range 0.86 to $1.03 \mathrm{~T}$ ( $\mathrm{B}_{\text {mirror }} / \mathrm{B}_{\text {center }}$ $\approx 2.0$ ). In the one instance where we present data at lower magnetic fields, we give the field values.

\section{Experimental Results}

A set of selected diagnostic signals from a single shot is shown in Figs. 3 and 4. The time (horizontal) scale is identical for all six signals. For this shot, the streaming plasma was on only during the middle portion of the time that the beam was passing through the chamber. The bean signal was obtained ifter the beam had transited the streaming plasma; this signal will be discussed later.

STREAMING IONS

From end-loss-detector signals such as those in FIg. 4, we obtained the ion-current profile and other data to follow. To arrive at these detectors, the particles had to pass through both north and south mirror ragions. We assume that the positive signals detected predominantly arose from the collection of ionized deuterium and titanium. The neutral beam was not present for the streaming-ion measurements summarized below.

Figure 5 shows the horizontal profile of the streaming-ion current obtained with the SELD gridded- detector plates. The biasing arrangement was similar to that shown in Fig. 2. The SELD signal levels in Fig. 5 were chosen at a time during the shot when most were at a maximum. They produce a well-defined profile, with a peak presumably located on the magnetic axis. Because Ion-current values in $\mathrm{F} i \mathrm{~g}$. 5 have been corrected for lossea on the grids, they represent the ion flux incldent on the first (outer) grid.

Figure 6 shows the vartical profile obtained from the end-loss data. We plot here the total streaming current per degree in the vertical direction, integrated over the horizontal direction, where the vertical angle $\theta$ is measured as shown in Fig. 1(b). The SELD plotted point is determined by multiplying the peak in Fig. 5 by the product of the $3.2-\mathrm{cm}$ horizontal full width at half maximum (FWHM) and the $\mathrm{cm} /$ degree conversion factor. To obtain the V-FELD plotted point, we use the experimentally measured clirrent flow, divide by the number of degrees subtended vertically by the plate, and correct for grid 
Dfscharge current. of streaming-plasma gun.

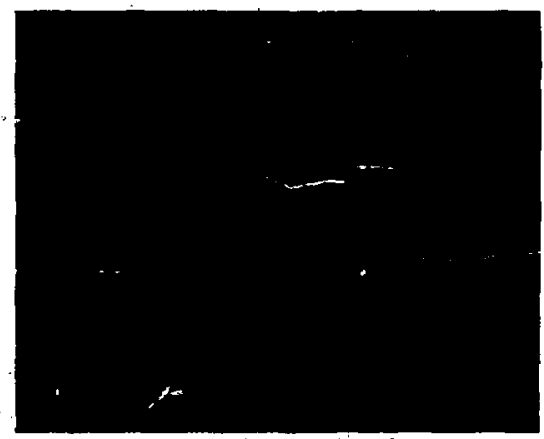

Transmitted beam.

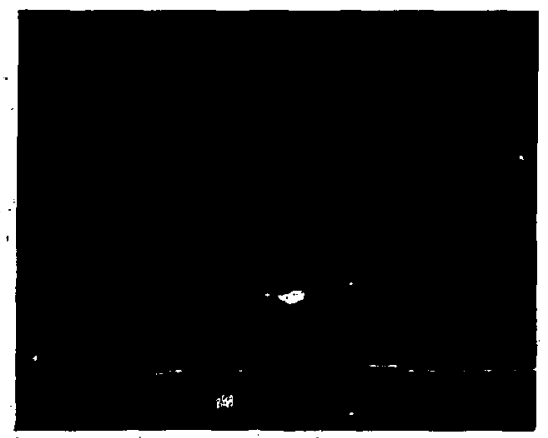

FAD.

F1g. 3: Partial set of diagnostlc signals for a beam-plus-stream shot. The time scale $1 s^{-}$the same for all traces ( $1 \mathrm{mb} / \mathrm{div}$ ). 


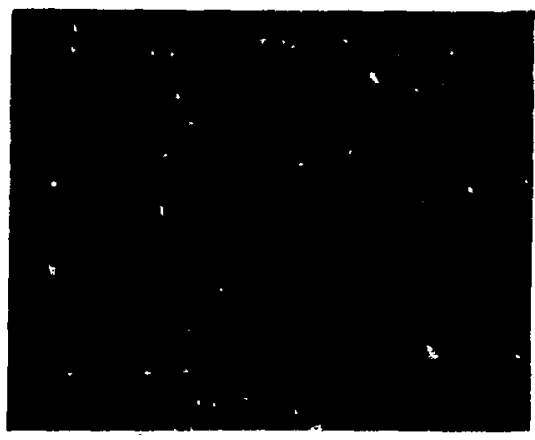

SELD *3.

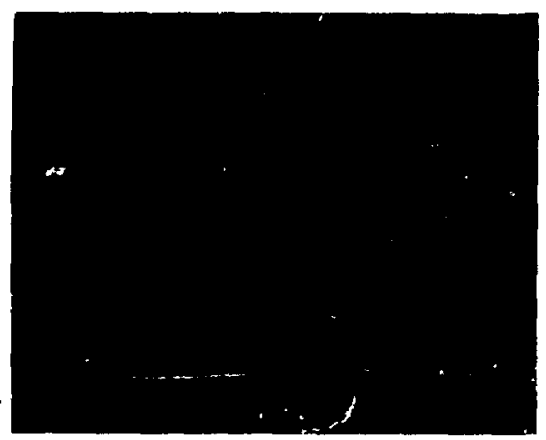

SELD $\$ 6$.

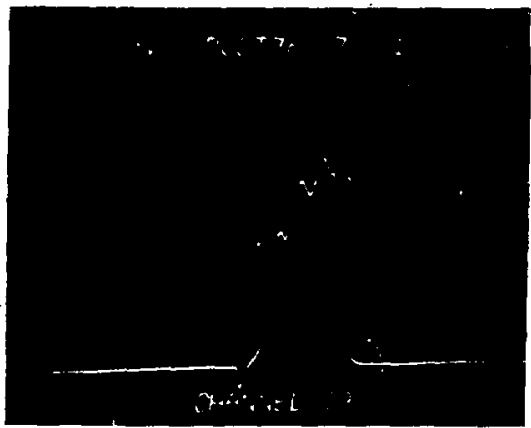

V-FELD.

F1g. 4. Continuation of Fig. 3, showing signals to three gridded-detector plates. 


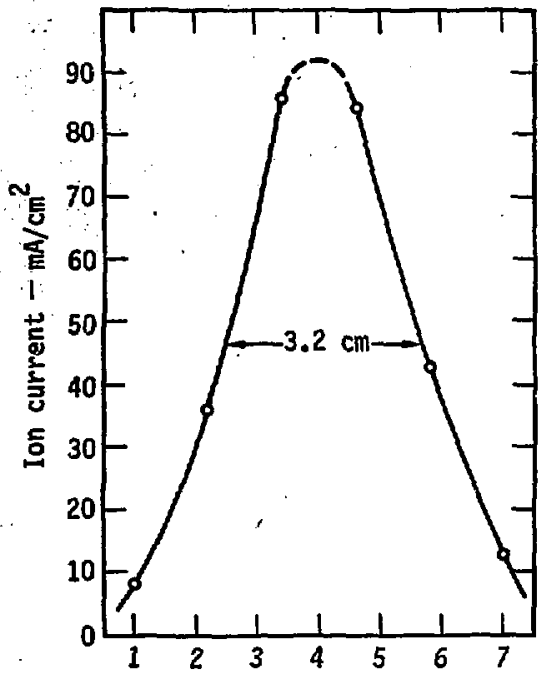

Relative horizontal position $-\mathrm{cm}$

F1g. 5. Horfzontal profile of streaming Ions at south chamber wall, as measured by the SIX SELD collector plates. Streamingplasma gun was in off-axis position. Ion-current magnitudes are corrected for losses on grids.

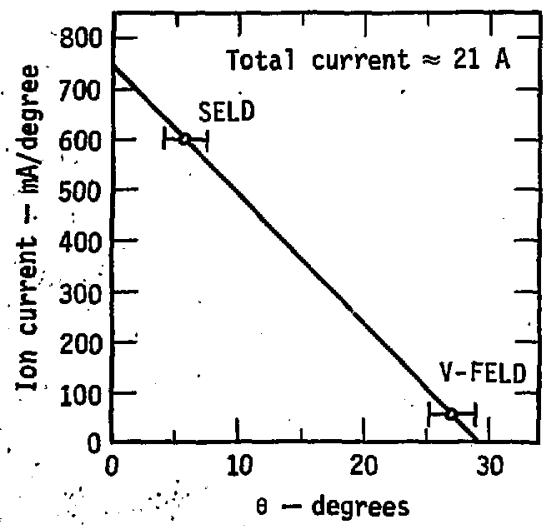

Fig, 6. Vertical profile of stream'Ing' Ions at south chamber wall, Incluaing the SEID results in Fig. 5 . losses as in Fig. 5. We assurie that the 1.9-cm width of the place covers nearly all of the horizontal profile in that region. The vertical angular extents of the SELD and V-FELD detector plates are indicated by the widths shown with each of the plotted points in Fig. 6.

By integrating over the vertical proftle in Fig. 6, we obtain $21 \mathrm{~A}$ as an approximation to the total streamIng-ion flux to the south wall of the vacuum chamber. To perform the integration, we make a simple, straightline fit to the vertical-profile data, as shown in F1g. 6 . We then Integrate over the triangular area and assume that the region below the magnetic axis contains an equal amount of streaming plasma.

Figure 7 shows the results of a computer analysis in which SELD

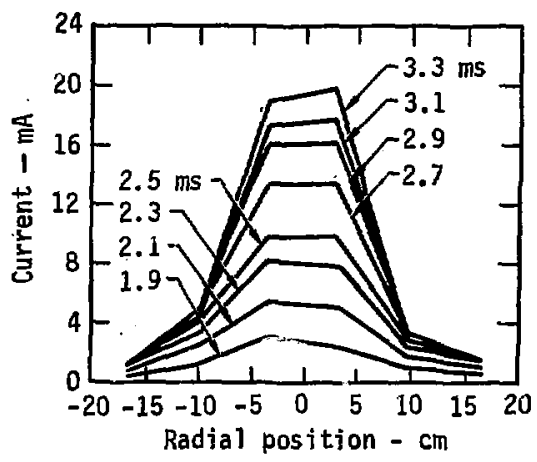

F1g. 7. SELD hortzontal current profile of ions at various relative times during a streaming pulse, projected along magneticfield lines to midplane. 
horizontal-profile streaming-ton data at various times during a shot are projected along magnetic-field lines to the midplane of the magnetic well. This transformation gives a much wider profile at the midplane than at the detector. The current levels here are those actually reaching the detector plates. Thus, unlike those in FIg. 5, these current values have not been normalized to unit area or corrected for grid losses. The plots in Fig. 7 show the shape of the horizontal streaming profile to change 1ittle during the streaming-plasma pulse.

In Fig. 8, we demonstrate how the signal levels at the SELD plates increased, on the averaie, as the ratio of the magnetic field at the mirror to that at the gun was decreased by moving the plasma gun toward the center along the magnetic axis. The daca indicate a factor of about four increase in streaming-plasma level for a factor of two decrease in magneticfleld ratio. The fleld ratio of 10.8 corresponds to our standard gun position, which was at the wall of the vacuum chamber. A lower effective mirror ratlo (or higher magnetic field at the gun) apparently makes it easier for the streaming-plasma particles to pass from the gun through the magnetic we1l.

Another way that we Increased the streaming-ion current to the SELD sollector plates was by ralsing the

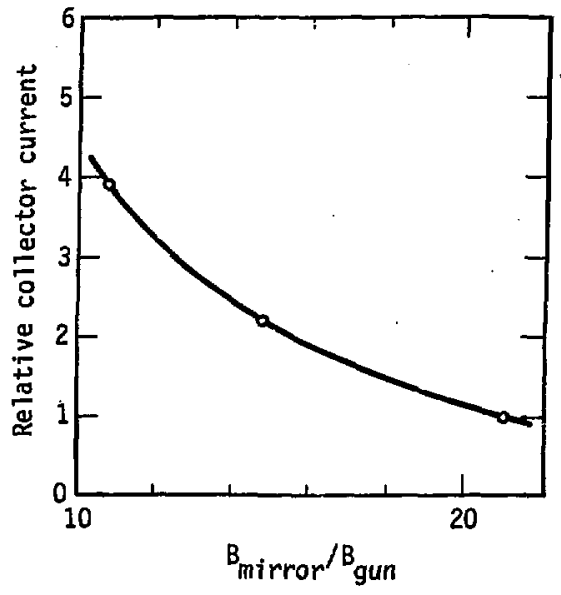

Fig. 8. SELD relative collector current versus $\mathrm{B}_{\mathrm{mirror}} / \mathrm{B}_{\text {gun }}$ as the streaming-plasma gun was moved toward the center of the magnetic well.

overall magnetic-fleld strength. Figure 9 shows this effect as the current in the BBII coll was ralsed so that the central fleld Increased from 0.52 to $1.03 \mathrm{~T}$. These data were obtained from computer plots such as those In FIg. 7; the profiles with maximum signal amplitude were used. (The profile data in Figs. 5 and 6 were acquired at $0.86-T$ central field, and those in $\mathrm{F} 1 \mathrm{~g} .7$, at $1.03 \mathrm{T.})$ Figure 9 shows that the peak detector current Increases with magnetic field, and the FWHM decreases relatively less, so that the product of the two, which is related to the total ion flux to the SELD, increases. Ralsing the magnet:c-fleld strength evident $1 y$ 


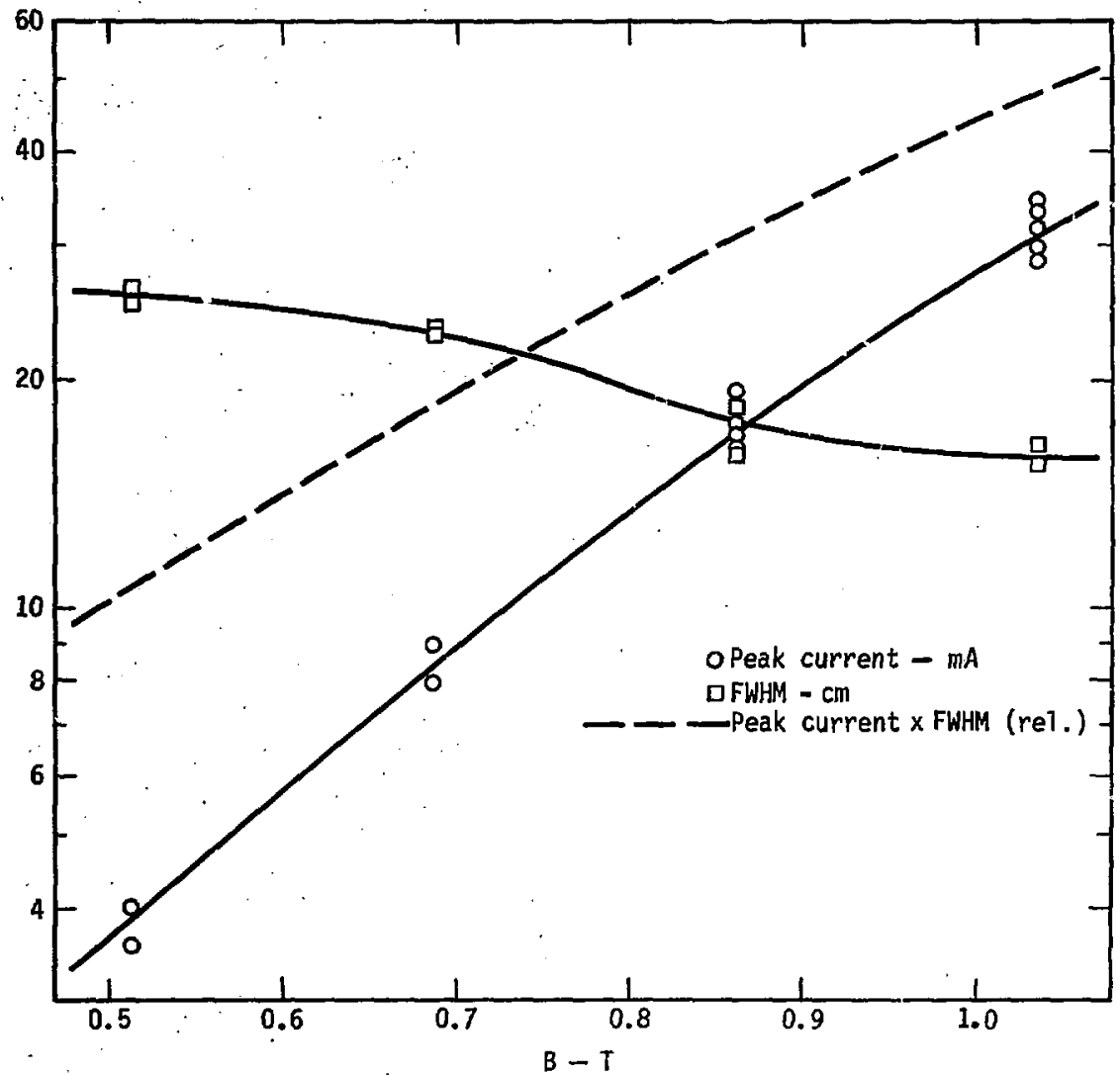

Fig. 9. Characteristics of the SELD streaming-ion profile (peak current, FWHM, and their product) at the midplane versus magnetic field at the center of the BBII coil. Streaming-plasma gun was in off-axts position.

facilitates the flow of the streaming plasma from the gun through the megneric well.

It is interesting to note that both methods just discussed for Increasing the SELD signals give an Increaise that varles approximately as the square of the magnetic-field strength at the gun. This increase in the ion current collected at the SELD presumably signifies augmented streaming-plasma line density at the center of the magnetic field. Supporting this conjecture is the 
observation that the beam attenuation caused by the streaming plasma

increases with higher magnetic fleld.

Retardation measurements of the streaming lons reaching the SELD give mean ion energles (if singly charged) of about 100 to $280 \mathrm{ev}$. The 1ower values were measured malnly in our first operation with the streaming gun. We obtained further measurements several months later after certain equipment changes had been made, e.g., modiflcations to the power supply for the streaming-plasma gun. The higher ion-energy results were acquired in this later experimentation. Because our measurement procedures 1mproved with time, the example shown in FIg. 10 is from the more recent data. He plot the measured peak positive SEID signal versus the positive voltage applied to the double grid (see Fig. 2). The curve drawn to fit these lata Is then numerically differentlated to obtain the dN/dE plot, from which a mean energy of about $280 \mathrm{eV}$ is calculated. One notes that the streaming Ions at the SELD have sizable range of energies, with about $19 \%$ of the zero-blas signal level remaining at a

* We ignore any distinction here between total and parallel energy because, even if most of the energy of an Ion is perpendicular to the magnetic-fleld lines when it passes through the mirror region, all but $13 \%$ of Its energy would be directed along the magnetic-fleld Ines when it reaches the gridded detector.

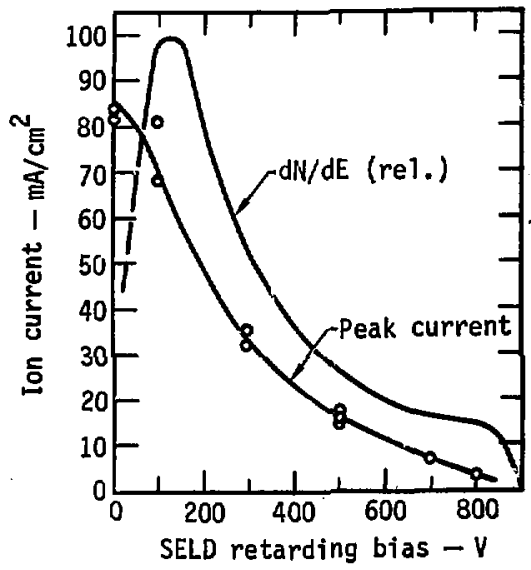

Fig. 10. Measured peak SELD plate current (cIrcles) corrected for grid losses, the curve drawn to fit these data, and derived plot of relative $d \mathrm{~N} / \mathrm{dE}$, all versus positive retarding bias. The fit to the data at the low-bias end is based on the data plotted plus data from another bias run (not shown).

$+500-V$ retarding blas and about $4 \%$ left at $+800 \mathrm{~V}$. For the quoted ion energies, we assume singly-charged particles. Any multiply-charged lons in the stream would have their energies scaled up accordingly.

Figure 11 shows the projections along magnetic-field lines to the midplane of the magnetic well of the SELD streaming-ion profile and of the emltting area of the streaming-plasma gun. The SELD profile used here was obtained when the washer gun was centered on-axts. It has a FWHM of $2.6 \mathrm{~cm}$ and a zero intercept for the vertical-profile plot of $32.7^{\circ}(70 \mathrm{~cm}$ 
(a) Horizontal

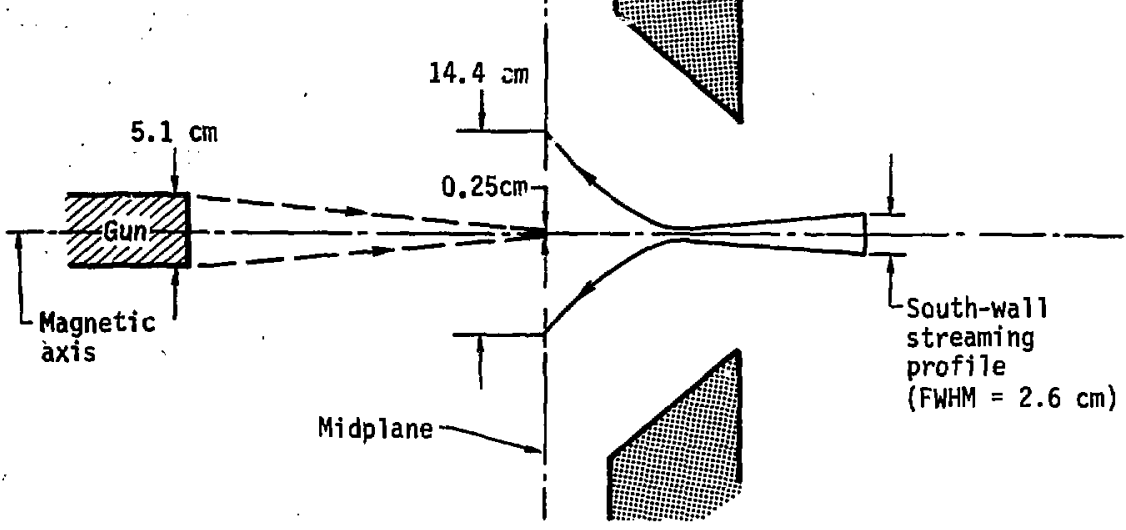

(b) Vertical

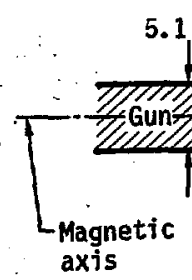

axis

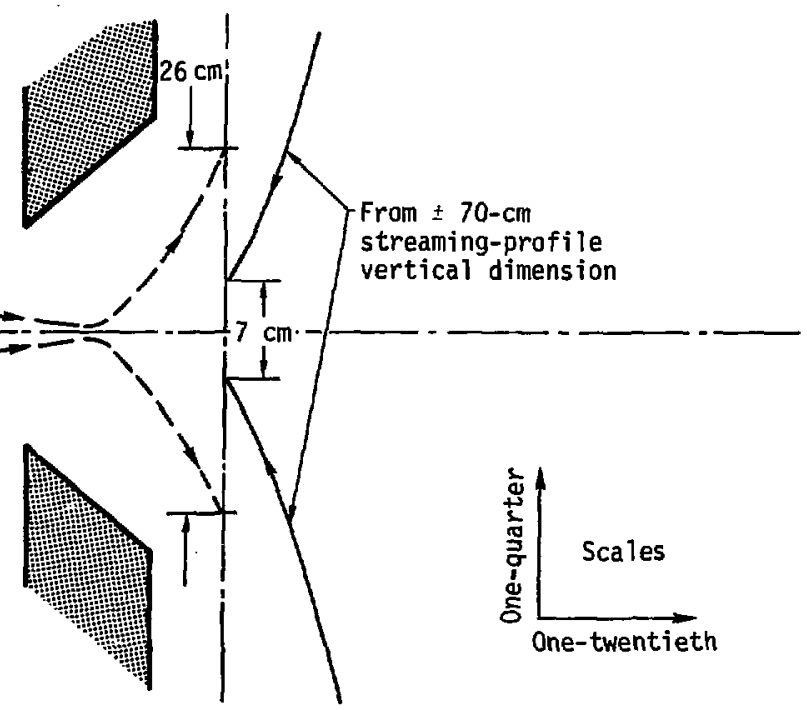

Fig. 11. Comparison. In the horizontal and vertical principal planes of the projections along magnetic-fleld lines to the midplane of the $5.1-\mathrm{cm}-\mathrm{diam}$ plasma gun and of the diriensions of the streaming-ion profile. The scales along and:-perpendicular to the magnetic axis are different, thus distorting the drawings. 
above the magnetic axis, near the V-FELD). The SEID projection to the midplane indicates a stream size there of about $14 \mathrm{~cm}$ horlzontally, perpendicular to the stream flow, and $\leq 7 \mathrm{~cm}$ vertica1ly. This is a good match to the neutral beam, which is about $6 \mathrm{~cm}$ high.

These projected streaming dimensions at the midplere are drastically different from those obtained by projecting the 5.1-cm-diam emitting area of the streaming plasma gun (about $0.25 \mathrm{~cm}$ horlzontally, about $26 \mathrm{~cm}$ vertica11y), as depicted In Fig. 11. This difference suggests mntion of the streaming plasma across magnetic-field lines, probably on the Input side where the densitieg are highest. The Inclusion of the charge-exchange processes $D^{+} Z D^{0}$ in the co-streaming $T i$ plasma furnishes one reasonable explanation for why the streaming plasma apparently diffuses rapidly across magnetic-field lines to form a cross section with a considerably different shape than expected.

STREAMING $\mathrm{n}_{\mathrm{e}}{ }^{\ell}$

We used the 2-mm microwave interferometer to obtain experimental measurements of the $n_{e} l$ (electron density $x$ thickness) of the streaming plasma along a horizontal line through the center of the magnetic well at an angle of $60^{\circ}$ to the stream flow.
Typical micr wave signals are shown in FIg. 12, together with traces indicatIng when the streaming plasma and neutral beam were passing through the magnetic well. Curves showing the time variation of $n_{e} e^{l}$, derived from signals such as those in Fig. 12, are plotted in Fig. 13. The curve through the experimental points in Fig. 13 that peaks at $\mathrm{n}_{\mathrm{e}} \ell \approx 1.7 \times 10^{14} \mathrm{~cm}^{-2}$ shows the time-dependent behavior of the streaming plasma during a typical pulse when the neutral beam was not on. Unlike the discharge current of the streaming-plasma gum, which is nearly constant during most of the pulse (see Fig. 12), the $n_{e}$ l results vary considerably with time.

These microwave measurements are consistent with the $n_{e} l$ value that can be approximately calculated from the observed attenuation of the neutral beam when it passed through the streamIng plasma. The average measured attenuation is about $12 \%$. An example of this attenuation 1 s seen during the stream-on part of the beam signal in Fig. 3. Attenuation measurements are corrected for a small electronic shift In the base line caused by the firing of the streaming gum. The $12 \%$ average attenuation figure Indicates that

$$
\text { on } \mathrm{e}^{\ell} \approx 0.12
$$

where $\sigma$ is the cross section for lonlalng the high-energy neutrals by 


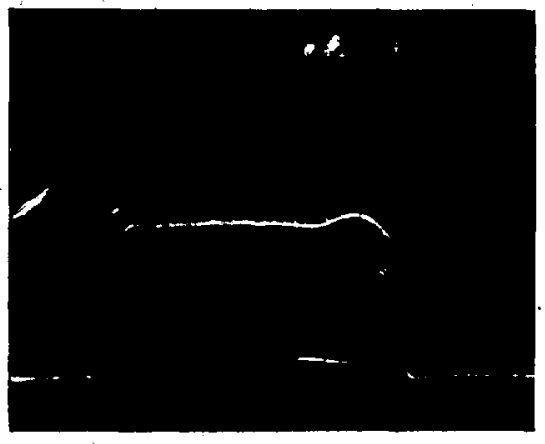

Discharge current of streaming-plasma gun.

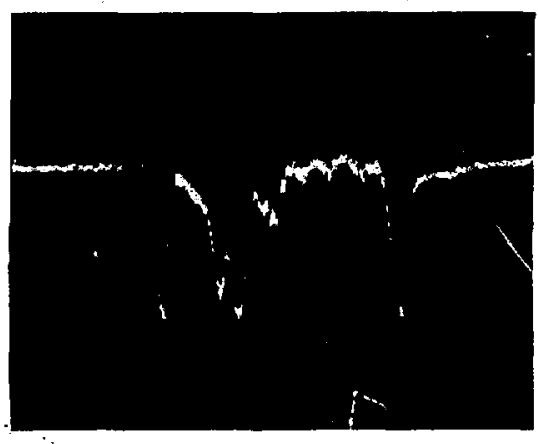

- Microwave $\cos \theta$ output.

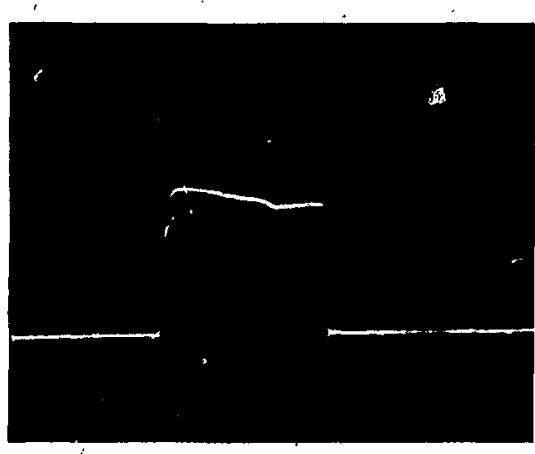

Beam acce1 voltage.

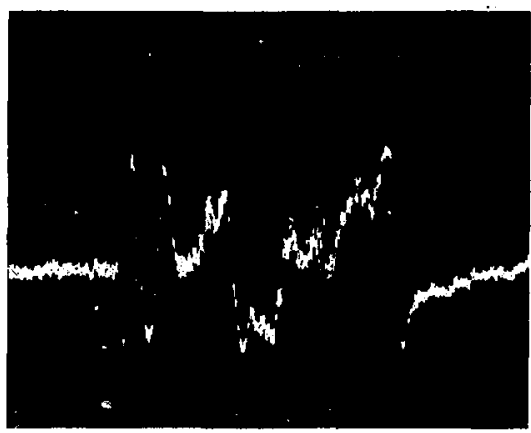

Microwave $\sin \theta$ output

F1g. 12. Typlcal microwave signals, along with traces showing times when the stream and beam were on. The time scale is the same for all traces. 
the streaming plasma (through chargeexchange and ionization processes), and $n_{e} l$ is again the streaming-plasma density (ions or electrons) times thicikess. For a 0 of $7.5 \times 10^{-16} \mathrm{~cm}^{2}$ (corresponding to fast $\mathrm{H}^{0}$ incident on $D^{+}$), Eq. (1) gives $n_{e} \ell=1.6 \times 10^{14}$. $\mathrm{cm}^{-2}$, a value in good agreement with that obtained from the microwave interferometer.

We now try to estimate the value of the streaming $n_{e} l$ at the midplane of the magnetic field from the measurements of the streming-ion current at the south wall. To do this calculation, we transform the measured profile of the horizontal current at the south chamber wall (e.g., see Fig. 5) to the midplane, taking into account the squeezing in of the profile in the vertical direction. An ion velocity is needed to calculate $\mathrm{n}_{\mathrm{e}}{ }^{l}$. If we assume $100-\mathrm{eV}^{+}$Ions, for example, this calculation gives $n_{\mathrm{e}} l \approx 3 \times 10^{12} \mathrm{~cm}^{-2}$ at the midplane, along a line in the horizontal direction perpendicular to the stream flow. If the fons are assumed to be $100-\mathrm{eV} \mathrm{T}_{i}^{+}$, a factor of about 5 higher value is obtained, i.e., $\mathrm{n}_{\mathrm{e}} \approx 1.5$ $\times 10^{13} \mathrm{~cm}^{-2}$. This is still a factor of about 10 below the measured $n_{e}$ ?" value, suggesting that streaming ions may be trapped in the magnetic well for a period of time.

Assuming that streaming ions are indeed transiently trapped, we can estimate their $\mathrm{nT}$ (density $\times$ containment time) value by fitting a buildup theory to the measurements of density and end-loss current. Two loss mechanisms are postulated: Coulomb scattering and charge exchange off energetic neutrals that are emitted into the loss cone from the streamingplasma gun. The equations used are

$$
\begin{aligned}
\frac{\mathrm{dn}}{\mathrm{d} t} & =\frac{I^{+}(t)}{\mathrm{eV}}-\frac{\mathrm{n}^{2}}{(\mathrm{n \tau})} \\
& -\frac{I_{\ell c}^{0}{ }^{\sigma} \sigma_{\mathrm{cx}} \mathrm{Ln} \exp \left(-\mathrm{n} \sigma_{\mathrm{tot}} \mathrm{L}\right)}{\mathrm{eV}},
\end{aligned}
$$

and

$$
\begin{aligned}
I_{S E L D} & =\frac{I}{2} \frac{n^{2} e V}{(n \tau)}+I_{\ell c}^{0}\left[1-\exp \left(-n \sigma_{t o t} L\right)\right] \\
& +F_{d} I_{\ell c}^{+}
\end{aligned}
$$

where

$I^{+}(t) \quad$ is the trapped current into the plasma,

$I_{\ell c}^{0} \quad$ is the input current of those neutral particles having'a velocity vectur lying in the loss cone,

$\mathrm{f}_{\mathrm{d}} \mathrm{I}_{\mathrm{lc}}^{+} \quad$ is the input current of those ions (a) having a velocity vector lying in the loss cone and (b) hitting the detector,

$\sigma_{c x}$ is the charge-exchange cross section,

$\sigma_{\text {tot }}$ is the total ionization cross section, including electron ionization and charge-exchange 
ionization of the neutrals, and

T. Is the 11fetime for Coulomb scattering.

A1so, $\dot{V}$ and $L$ are the volume and length, respectively, of the trappedIon plasma, and $e$ is the elementary charge. The plasma density $n(t)$ is measured by the microwave interferometer. The rate of change of density an/dt Is obtained by differentlating the microwave data. The last term in Eq. (3) Is neglected in this analysis. It 18 assumed small because the magnetic-field lines that intercept the circular gun form a long, thin, ver- tical ellipse at the oppostte chamber wa11. Thus, the fraction $\mathrm{f}_{d}$ of $\mathrm{I}_{\ell_{c}}^{+}$ that is incident on the SELD detector 1s sma11. The free parameters $n \tau$ and $I_{l_{c}}^{0}$ In Eqs. (2) and (3) are varied to obtain the best fit to the SELD data. The trapped current into the plasma is then calculated by solving Eq. (2) for $I^{+}(t)$.

The data shown In Figg. 7 and 13 are best fit with $n \tau \approx 2 \times 10^{9} \mathrm{~s} / \mathrm{cm}^{3}$ and $I_{l_{c}}^{0} \approx 1 \mathrm{~A}$, when we use Eqs. (2) and (3). This value of $n \tau$ is consistent with the measured average end1088 energy of $280 \mathrm{eV}$ if one assumes that the trapped ion energy is $400 \mathrm{eV}$

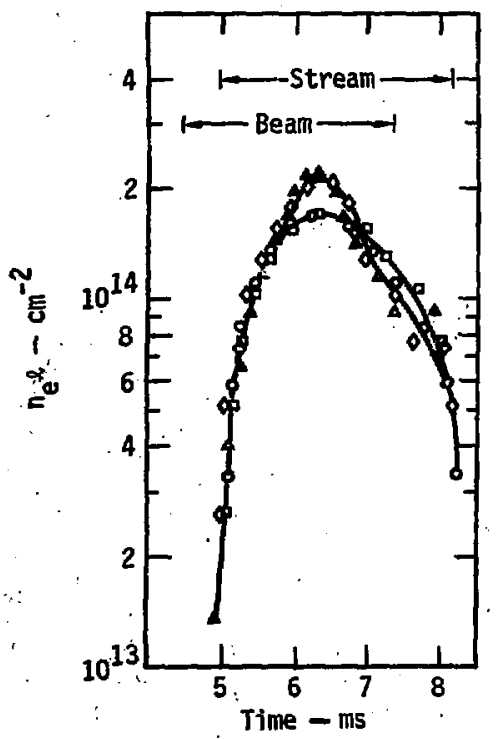

\begin{tabular}{|c|c|l|}
\hline Symbol & $\begin{array}{l}\text { Shot } \\
\text { no. }\end{array}$ & Conditions \\
\hline 0 & 2 & Stream only \\
0 & 4 & Stream + beam \\
$\Delta$ & 5 & Stream + beam \\
0 & 6 & Stream only \\
\hline
\end{tabular}

F1g. 13: Results of microwave measurements of $n l$ versus time during four $\therefore$ experimental shots, two with streaming plasma only passing through the magnetic vel1, and two with neutrc 1 beam as well as stream. 
(as indicated by Fokker-Planck calculations), with the low-energy end of the trapf ad-ion distribt tion being 1ost. 'Iue trapped current is calculated to increase monotonically with time.

OBSERIPATIONS DURING NEUTRAL-BEAM INJECTION

In Fig. 13, the curve through the $\mathrm{n}_{\mathrm{e}} l^{l}$ experimental points with the higher magnitude peak is that obtained when both the plasma stream and the neutral beam were present. The difference $\left(n_{e} l \approx 4 \times 10^{13} \mathrm{~cm}^{-2}\right.$ ) between that peak and the one measured with the stream only is assumed to represent the effect of the hot ions that are trapped due to the interaction between the neutral beam and the plasma stream. To minimize any uncontrolled experimental variations, the four shots plotted in Fig. 13 were taken during a short time period.

If we divide the Increase in $\mathrm{n}_{\mathrm{e}}^{\ell}$ of about $4 \times 10^{13} \mathrm{~cm}^{-2}$ by $\mathrm{in}$ assumed average path length of $13 \mathrm{~cm}$, we obtain an increase in electron density of $3( \pm 1) \times 10^{12} \mathrm{~cm}^{-3}$. The quoted error is an estimate of the statistical reproducibility of the microwave data. The systematic error in $n_{e}{ }^{l}$ is assumed to be small compared with the statisticai varlation. The value of average path length is estimated from the projected streaming-ion FWHM of
$14 \mathrm{~cm}$, adjusted for the $60^{\circ}$ microwave angle and the decreased plasma thickness above and below the horizontal midplane.

HOT-ION DENSITY

The measured increase in electron density when both the plasma stream and the neutral beam were present can be interpreted as the density of trapped hot ions. Support for this Interpretation comes from the good agreement between this measured increase and a value calculated from the buildup equation. The characteristic hot-icn loss time needed in this calculation can be estimated from the decay of the interferometer signal when the neutral beam was turned off. Decay times between about 0.1 and $0.5 \mathrm{~ms}$ were observed. Because these times are short compared with the beam-on time, equilibrium was obtained. Therefore, we can write

$$
\mathrm{n}_{\mathrm{H}}^{+} \approx \frac{\mathrm{I}_{0} \mathrm{f}_{\mathrm{t}}}{\mathrm{eV}^{\mathrm{V}}} \tau_{\text {loss }},
$$

where $n_{H}^{+}$is the hot-1on density, $I_{0}$ is the injected neutrai-beam current, e is the elementary charge, $f_{t}$ is the fraction of the beam trapped, $V$ is the volume of the hot-ion plasma, and ${ }^{\tau}$ loss is the characteristic ion loss time. Substituting $I_{0} / e=33 \mathrm{~A} \times 6.25$ $\times 10^{18}$ particles $/ \mathrm{A} \cdot \mathrm{s}, \mathrm{f}_{\mathrm{t}}=0.12$, $\mathrm{V}=2.5 \times 10^{3} \mathrm{~cm}^{3}$, and a mean value 
for the loss time of $0.3 \mathrm{~ms}$, we obtain $\mathrm{n}_{\mathrm{H}}^{+} \approx 3.0 \times 10^{12}$ Ions $/ \mathrm{cm}^{3}$, a value in agreement with the measured increase in electron density.

\section{EFFECTS OF PLASMA-STREAM}

\section{COMPOSITION}

Interpreting the Increase in electron density in terms of a hot-ion density is open to some question because of the unknown composition of the streaming plasma from the gun. There ts evidence from earlier work ${ }^{3}$ that the streaming plasma from such a source, when the source Is operated In the 1ong-pulse mode of Interest here, contains $D^{0}$ and Ionized-TI fractions. Qualitative measurements of the BBII-T streaming plasma showed that both $\mathrm{D}^{0}$ and $\mathrm{TI}^{+}$were present: two monochromators aimed at the central magneticfield region were tuned to wavelengths appropriate to $\mathrm{D}^{0}$ and $\mathrm{TI}^{+}$, and IInes for both were observed ( $\mathrm{TI}^{+}$being the strongest) throughout the duration of the streaming-plasma pulse.

The effect of $\mathrm{TI}^{+}$or $\mathrm{D}^{0}$ components in the stream would be to cause loss of trapped hot lons through charge exchange. The streaming $\mathrm{D}^{0}$ equivalent current can be estimated from Barr's measurements, 8 allowing us to place an upper limtt of about $6 \mathrm{~A}$ through the BBII-T plasma volume: At this level, the $\mathrm{D}^{\mathrm{O}}$ flux would not limit the hot-ion density.
The effect of trapped TI lons is more difficult to determine. We have estimated this effect, considering ionization and scattering lifetimes for the various charge states of $T_{i}$ in the trapped streaming plasma. If we assume $5 \mathrm{~A}$ of $\mathrm{TI}^{+}$trapped and use the best values available for the chargeexchange cross sections Involved, we estimate that a hot-Ion denstty of $\approx 2 \times 10^{12} \mathrm{~cm}^{-3}$ could be realized. The actual $\mathrm{Ti}^{+}$current is not known, but It probably cannot exceed 10 to $15 \mathrm{~A}$ because It would then, stripped to $\mathrm{Ti}^{++}$, account for most of the observed end-loss current. If the $\mathrm{TI}^{+}$ mrent were Indeed this hIgh, the hot-Ion density would be 1Imtted by charge exchange to $\leq 1 \times 10^{12} \mathrm{~cm}^{-3}$.

If charge exchange on $\mathrm{T} 1$ lons does IImit the hot-1on density to $<3 \times 10^{12} \mathrm{~cm}^{-3}$, we must explain the extra increase in electron density observed during neutral-beam injection In terms of additional ionization of Ti. Without beam Infection, we estimate that the fate of most of the $\mathrm{Ti}^{+}$Ions is to be Ionized to $\mathrm{Ti}^{+++}$and then scattered out. To account for the Increase in electron density with beam Injection, significant numbers of $\mathrm{TI}^{+++}$must be tonized to $\mathrm{TI}^{\mathrm{H+}}$ before the scattering loss occurs. Even then, the Increased charge state is counterbalanced by the shorter scatterlng time of the $\mathrm{TI}^{+++}$. Our modeling of the streaming plasma is 
sufficiently complex and uncertain that we must leave open the possibility that some fraction of the increase in electron density is due to ionization effects.

At higher injected neutral-beam equivalent currents, we would expect the $\mathrm{Ti}^{+}$density to decrease because of ionization and charge exchange to the higher charge states where chargeexchange cross sections become negligible. The hot:-; in lensity would then increase until other losses deminate, as observed in the $2 \mathrm{XI}: \mathrm{B}$ experiments. 5,9

BACKGROUND-GAS DENSITY

In the density regime where all neutral gas incident on the plasma is ionized, the charge-exchange flux is independent of the plasma density. In this "burn-out" condition, the charge-exchange flux is a measure of the density of the neutral gas that is incident on the plasma, not of the density of the trapped hot ions. We assume here that the energetic, charge-exchange flux is dominated by charge exchange with thermal gas because the measured charge-exchange flux is an order of magnitude too large to be accounted for by resonance charge exchange with the beam.

We used a surface-barrler detectior operating in the current mode, located below the midplane, -o measure the charge-exchange flux when both the neutral beam and the streaming plasma were passing through the chamber. The measurements showed a charge-exchange flux of fast neutrals at the detector of approximately $5 \times 10^{13}$ particles/ $\mathrm{cm}^{2} \cdot \mathrm{s}$. From geometrical considerations, and assuming that the flux is isotropic, we estimate that this corresponds to a total charge-exchange flux of $1.1 \times 10^{19}$ particles/s. From this value of total chargeexchange flux, we now estjmate the density of the background gas. As the incident background thermal neutrals impinge upon the plasma, they underg.) either charge-exchange or ionizing collisions with the plasma in the boundary region. We assume, for now, th.at the ion and alectron energies of the cold streaming plasma at the boundary are too low to contribute significantly to the ionization of the thermal flux. Then, the fraction of the neutral gas incident on the plasma that contributes to the measurea energetlc charge-exchange flux at the detector is $\sigma_{\mathrm{cx}} /\left(\sigma_{\mathrm{cx}}+\sigma_{1}\right)$, where $\sigma_{\mathrm{cx}}$ and $\sigma_{1}$ are the cross sections for charge exchange and ionization, respectively, of the thermal flux by the hot-ion plasma. Therefore, we write

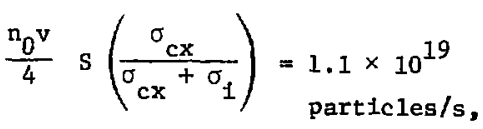

where $\mathrm{n}_{0}$ is the density of the background gas, $v$ is its average veloctty, 
and $S$ is the surface area of the

plasna. Substituting $\mathrm{v}=1 \times 10^{5} \mathrm{~cm} / \mathrm{s}$, $s=2.5 \times 10^{3} \mathrm{~cm}^{2}, \sigma_{c x}=7.5 \times 10^{-16}$ $\mathrm{cm}^{2}$, and $\sigma_{1}=1 \times 10^{-16} \mathrm{~cm}^{2}$, we obtatn

$$
n_{0} \approx 2 \times 10^{11} \text { neutral } / \mathrm{cm}^{3} .
$$

To the extent that the cold plasma contributes to the Ionization of the neutral gas, our estimate of $n_{0}$ should be raised. Charge exchange of hot Ions on the streaming plasma or neutrals would tend to lower the $n_{0}$ estimate.

\section{Concluding Remarks}

The experimental results presented here, obtained for the steady-btate magnetic fisld of the BBII superconducting col1, are consistent with those observed in the pulsed 2XIIB experiment. Supplementary data have been obtained on the spatial profile and energy distribution of the streamIng ions. Evidence suggests that higher magnetic-field magnitudes give largér streaming-plasma denstities.
With the 1Imfted neutral-beam current available for the BBII-T experimentation, we could not expect to bulld up to the density range of $2 X I I B$, and Indeed we did not. However, we have been able to show that the target plasma produced by the stream appears suitable for both instability control (based on 2XIIB expertence ${ }^{5}$ ) and neutra1-beam trapping ${ }^{9}$ in the BBII magnetic field.

\section{Acknowledgments}

We wish to acknowledge the essential assistance in this experiment of the BBII-T operators, technictans, and other support personne1; of H. Kefth Mortensen and Alfred F. Waugh, Elec- tronics Engineering Department, Fustion Energy Systems Division; of Stanley R. Thomas, Jr., Mechanical Engineering Department, Energy Systems Division; and of Walter $\mathrm{C}$. $\mathrm{Ng}$, Computations. 


\section{References}

1. BasebalZ II-T Progrom Plan and Najor Project Proposal, Lawrence Livermore Laboratory, Rept. LLL-Prop-126 Rev. 1 (1975).

2. F. H. Coensgen, W. F. Cummins, and A. E. Sherman, "Multistage Magnetic Compression of Highly Ionized Plasma," Pigs. Fluids 2, 350 (1959).

3. J. F. Stelnhaus, N. L. Oleson, and W. L. Barr, "Investigation of a Plasma from an Occluded Gas Cold Plasma Source," Phys. Fluids $\underline{8}, 1720$ (1965).

4. G. D. Porter, C. C. Damm, J. H. Foote, A. H. Iutch, R. K. Goodman, R. S. Hornady, and J. E. Osher, PZasma Production by Laser-PeZZet Interaction in Baseball II-T, Lawrence LIvermore Laboratory, Rept. (In preparation).

5. F. H. Coensgen, W. F. Cummins, B. G. Logan, A. W. Molvik, W. E. Nexsen, T. C. Simonen, B. W. Stallard, and W. C. Turner, "Stabilization of a Neutral-Beam-Sustained, Mirror-Confined rlasma," Phys. Rev. Lett. $\underline{35}$, 1501 (1975).

6. D. E. Baldwin, H. L. Berk, and L. D. Pearlstein, "Turbulent Lifetimes in Mirror Machines," Phys. Rev. Lett. 36, 1051 (1976).

7. Archer H. Futch and W. Keith Mortensen, A 2-mm Microwave Interferometer, Lawrence Livermore Laboratory, Rept. UCRL-52245 (1977).

8. W. L. Barr, "A Pulsed Source of Fast Hydrogen Atoms," J. I'rpl. Phys. 42, 5411 (1971).

9. F. H. Coensgen, W. F. Cummins, C. Gormezano, B. G. Logan, A. W. Molvik, W. E. Nexsen, T. C. Simonen, B. W. Stallard, and W. C. Turaer, "Startup of a Neutral-Beam-Sustained Plasma in a Quasi-dc Magnetic Field," Phys. Rev. Lett. 37, 143 (1976). 